\title{
Criterion for Interlaminar Strength of CFRP Laminates Toughened with Carbon Nanofiber Interlayer
}

\author{
Masahiro Arai ${ }^{\mathrm{a}}$, Kazutoshi Matsushita ${ }^{\mathrm{b}}$, Satoshi Hirota ${ }^{\mathrm{c}}$ \\ ${ }^{a}$ Department of Mechanical Systems Engineering, Shinshu University, \\ 4-17-1, Wakasato, Nagano, 380-8553, Japan \\ ${ }^{b}$ Toyota Auto Body, CO., LTD., 100 Kanayama Ichiriyama-cho, Kariya, Aichi \\ 448-8666, Japan \\ ${ }^{c}$ Graduate Student, Graduate School of Shinshu University, 4-17-1, Wakasato, Nagano, \\ 380-8553, Japan
}

\begin{abstract}
The criterion for the interlaminar strength of unidirectional carbon- fiberreinforced plastic (CFRP) laminates is discussed. To evaluate the limit curve given by the relation between normal stress and shear stress on the fracture interface, two types of interlaminar strength tests were carried out using short beams of CFRP laminates. The criterion for the interlaminar fracture of the CFRP laminates was investigated in two-dimensional finite element analysis of the CFRP specimens. Interlayers made by carbon nanofiber were inserted between the prepregs of the CFRP laminates. A modified 'Tsai-Wu' criterion was employed to evaluate the critical curve of the interlaminar fracture of the CFRP laminates. The effect of the CNF interlayer on the criterion of the interlaminar strength of CFRP laminate is discussed in detail.

Keywords: Carbon Fiber; Nanostructures; Interface/Interphase;

Mechanical Testing
\end{abstract}




\section{Introduction}

In the past several decades, fiber-reinforced plastics have been developed as highly useful materials for use in fields such as mechanical, electrical, architectural, and structural engineering. In particular, carbon-fiber-reinforced plastic (CFRP) has been widely used as a structural material for use in aeronautical and space engineering. Application in this industry requires further weight reductions to satisfy the demand for higher fuel efficiency. In the Boeing 787 project, a considerably improved weight ratio due to the adoption of CFRP for the main wing and fuselage was reported[1].

To extend the engineering application fields of CFRP laminates, it is necessary to improve the strength and fracture toughness of CFRP laminates. Various methods of improving the interlaminar fracture toughness and interlaminar strength have been proposed. Previous attempts to improve the interlaminar fracture toughness of CFRP laminates have provided various useful results. Specifically, a certain level of toughening has already been achieved by inserting an interleaf (interlayer) between the CFRP prepregs[2]-[5]. T800H/3900-2, with a heterogeneous interlayer consisting of fine thermoplastic particles, has shown high compressive strength after impact. Ionomer-interleaved CFRP laminates have shown higher toughness under mode II deformations[6].

Since the discovery of the carbon nanotubes (CNFs) in the 1970s[7, 8] and the publication in Nature for the clarification of the structure of carbon nanofibers (CNFs) [9], CNTs and CNFs have received a great deal of attention in the aeronautical, biological, electrical, mechanical, and engineering fields. Owing to the superior electrical conductivity of CNF, multi-walled 
CNTs and vapor-grown carbon fiber (VGCF) have been widely used in storage batteries and as conductive filler.

In addition, CNTs and CNFs have been applied as a toughening filler for resin- or metal-based composites[10, 11, 12]. They are suitable for such application as they also have excellent mechanical properties such as elastic modulus, strength, and fracture toughness compared with traditional carbon fiber based on polyacrylonitrile.

The authors' group has already presented an alternative method to increase the interlaminar fracture toughness of CFRP laminates using CNFs, in which the toughening interlayer, composed of CNF, is inserted between CFRP prepreg sheets[13, 14]. VGCF has been employed as the stiffener of the interlayers for a unidirectional CFRP laminated beam, where mode I and II interlaminar fracture toughness values of the composite were evaluated in double cantilever beam and end-notched flexure tests using unidirectional CFRP beam specimens.

In the present study, the interlaminar strength of unidirectional CFRP laminates toughened with a VGCF interlayer is discussed. The criterion for interlaminar strength was investigated in interlaminar strength tests carried out for CFRP laminated beams. Generally, interlaminar shear strength (ILSS) tests of the CFRP were measured in a three-point bending test with a short-type beam, where the ILSS values were evaluated by an approximated equation from only the shear stress on the interface. However, in nature, the criterion of the interlaminar fracture should be discussed on the basis of the multi-axial stress condition of a specimen.

To obtain the limit curve that is given by the relation between the normal 
stress and shear stress on the fracture interface, two types of interlaminar strength test were carried out in the present study. One is a 'compressiontype test' employing simple three-point bending, where the compressive load in the vertical direction is applied to the top surface of the beam specimen. The other is a 'tensile-type test', in which shear tensile loading is applied to specimens with a hole using a shear pin and a vertical load is applied to the shear pin to impart tensile normal stress on the interlaminar layer.

The criterion for the interlaminar fracture of the CFRP laminates was investigated in two-dimensional finite element analysis of the CFRP specimens. Two types of CFRP laminates were used in the present study. One is a general unidirectional CFRP laminate comprising prepregs made with an autoclave. The other is a nano-modified CFRP laminate in which the interfaces of the prepregs are toughened with CNF. The criterion for the interlaminar fracture of the CFRP laminates was discussed in terms of the modified 'Tsai-Wu' criterion[15]. The effect of the CNF interlayer on the criterion of interlaminar strength of the CFRP laminate was investigated in detail.

\section{Interlaminar strength tests of CFRP laminates}

\subsection{Test procedure}

To evaluate the criterion for interlaminar damage of CFRP laminates, two types of interlaminar strength tests were carried out. The first type, shown in Fig. 1, is a general three-point bending test like the standard ILSS test[16] using short-beam specimens. In this test, compression stress in the direction transverse to the beam is applied to the center part of the specimen. 
This method is referred to as the 'compression-type test' hereafter.

The second type, shown in Fig. 2, is a three-point bending test using a shear pin. In this test, a hole through the laminate (diameter of $4.0 \mathrm{~mm}$ ) was open to the side of the specimen. The shearing pin was inserted in the hole and transverse loading was applied to the shearing pin. In this method, the stress in the direction transverse to the beam is positive. Hereafter, the method is referred to as the 'tensile-type test'.

In the compression-type test, the support length was changed between 14 and $19 \mathrm{~mm}$ to control the ratio of normal stress and shear stress. Similarly, the support length was changed between 19 and $38 \mathrm{~mm}$ in the tensile-type test. A universal material testing machine AG-100kNE (Shimadzu Co.) was used for the experimental tests. The cross-head rate was set to $0.1 \mathrm{~mm} / \mathrm{min}$. The maximum load, at which point interlaminar damage occurred in the CFRP laminate, was measured. Finite element analyses for the CFRP laminated beam were carried out to obtain the internal stress components at the position at which initial damage occurred.

\subsection{CFRP specimens}

CFRP laminates were made using an autoclave AA-1710-048-M (APC Aerospecialty Inc.) in our laboratory. The specimens were composed of carbon/epoxy prepreg (TORAY P3052S-22, fiber:T700S, matrix:\#2500) and a CNF interlayer. In the present study, VGCF (Showa Denko K. K.) as shown in Fig. 3 was used as the stiffener for the interlayer. The diameter of the VGCF is about $150 \mathrm{~nm}$, the mean length is $10 \mu \mathrm{m}$, bulk density is $2.0 \mathrm{~g} / \mathrm{cm}^{3}$.

Powder of CNF was inserted between prepregs of the CFRP specimens 
with an area density of $10 \mathrm{~g} / \mathrm{m}^{2}$ using a sifter[14]. An interlayer of $50 \mu \mathrm{m}$ mean thickness was naturally formed by the fusion of CNF and epoxy resin leaking into the interlayer during the production of the specimens as shown in Fig. 4. The volume fraction of CNF in the interlayer is about $10 \%$. The specifications and dimensions of the CFRP specimens for compression-type and tensile-type tests are presented in Table 1.

\subsection{Experimental results}

The relations between applied load and displacement obtained in the compression-type tests are shown in Fig. $5(L=14 \mathrm{~mm})$ and Fig. $6(L=19 \mathrm{~mm})$ respectively. In the compression-type tests, the relations show some nonlinearity in the neighborhood of the maximum value.

Figures 7 and 8 show the relations between applied load and displacement obtained by tensile-type tests. In these figures, the curves representing the load-displacement relations are initially convex and then indicates peak value with the initial damage.

Note that the displacement in the Figs 5, 6, 7 and 8 were measured by the cross head rate and elapsed time in the experiments. Therefore, the value of displacement has the possibility of containing error margins of the test device.

The locations of initial damage for the different types of specimen are shown in Figs. 9, 10, 11 and 12. In the present study, the location of initial damage was observed on the side of the specimen using optical microscope. Although it is essentially difficult to identify the exact location of the initial damage, the initial damages generally occur near the loading point, and the initial damage progresses to the longitudinal direction of the specimen away 
from the loading point. Therefore, we identified the nearest point from the loading point in the crack as the location where the initial damage occurs.

From Figs. 9, 10, 11 and 12, It is found that the location of initial damage differs even if the experimental condition is the same. That is, to evaluate the damage criterion, it is necessary to consider the location of damage and multi-axial stress state in each specimen.

\section{Finite element analysis}

In the present study, the interlaminar strength tests of the CFRP laminates were simulated by finite element analysis. FEM analyses were executed using a two-dimensional section model of the CFRP laminated beam as shown in Fig. 13 (for the compression-type tests) and Fig. 14 (for the tensiletype tests). For FEM analyses, an universal finite element program ANSYS ver.10.0[17] was employed. The compression-type model was divided into 2236 quadratic elements (Element type; PLANE183) as shown in Fig. 13, whereas the tensile-type model was divided into 3189 quadratic elements as shown in Fig. 14.

The CFRP beam was analyzed by plane stress conditions because the width of the specimen is too small. Since the CFRP specimen is not restrained in the direction of width, the normal stress to the direction of width obviously becomes small. In addition, we found that the primary crack is generated on the side surface of the specimen, and seems to progress inside the specimen afterwards. Therefore we thought that the component of stress in the direction of width was not too important in the present study, and we judged that it was preferable to analyze the CFRP specimen by a plane 
stress condition by occasion of above.

In the tensile-type specimen, the load was applied on the top point of the shearing pin. The shearing pin contacts to the specimen at the bottom surface of the pin. Therefore, the vertical load is applied to the lower surface of the hole in the the specimen. The contact condition between the shearing pin and hole surface was treated as elastic tangency of friction coefficient 0 .

In the present FEM analyses, analytical models were assumed to be a homogeneous orthotropic bodies. The elastic moduli of the CFRP base laminates and CFRP laminates toughened with a CNF interlayer are presented in Table 2. The subscripts ' $L$ ' and ' $T$ ' in the table denote the longitudinal and transverse directions of the CFRP beam respectively.

The elastic moduli of the CFRP laminates were measured by standard tensile test. $G_{L T}$ was estimated by the following equation using $E_{45^{\circ}}, E_{L}$, $E_{T}$ and $\nu_{L T}[18]$ :

$$
\frac{1}{G_{L T}}=\frac{4}{E_{45^{\circ}}}-\frac{1}{E_{L}}-\frac{1}{E_{T}}+\frac{2 \nu_{L T}}{E_{L}}
$$

However, in the specimens with interlayer, it is difficult to determine the parameter $E_{T}, G_{L T}$ by the standard tests. Hence, these parameter were estimate by homogenization theory using FEM analyses. In FEM analyses, the Young's moduli of the interlayer were specified to 5.77GPa, which was estimated by Vickers Hardness (VH) using a Micro Vickers testing machine (DUH-201, Shimadzu Co.).

In the present FEM analyses, the layered structure of CFRP was not considered, and the structure was treated as a homogeneous, anisotropic body as previously mentioned. In the analyses with the homogeneous body, some stress and strain components become different to those obtained by layered 
structure. However, by the FEM analyses using homogenization theory, it was confirmed that the stress $\sigma_{T}$ (to the direction of the thickness) and $\tau_{L T}$ (shear stress for the out of plane) are almost corresonding between layered and homogenized structure.

Figs 15, 16 and 17 are numerical results of $\sigma_{L}\left(=\sigma_{x}\right), \sigma_{T}\left(=\sigma_{y}\right)$ and $\tau_{L T}\left(\tau_{x y}\right.$ on the point of initial damage using the FE model of Fig. 13. In these figures, a central part is a prepreg layer, and an upper and lower thin layer is CNT interlayer. As shown in Fig. 15, the distribution of the normal stress $\sigma_{L}$ is obviously different in the interlayer and the prepreg layer. On the other hand, it is confirmed that the normal stress $\sigma_{T}$ and the shear stress $\tau_{L T}$ takes quite the same value in the prepreg layer and the interlayer as shown in Figs 16 and 17.

As described later, only stress components $\sigma_{T}$ and $\tau_{L T}$ are used to evaluate the criterion for the interlaminar strength of CFRP. Therefore, it was judged that the analyses using homogenized structure are valid for the present discussion.

Examples of contour figures of normal stress $\sigma_{T}$ and shear stress $\tau_{L T}$ obtained in finite element analyses are shown in Figs. 18 and 19. In the following section, interlaminar damage criteria of the CFRP laminated beams are discussed in terms of the stress components obtained in FEM analyses.

\section{Evaluation of the damage criterion}

\subsection{Modified Tsai-Wu damage criterion}

The state of a multi-axial stress greatly influences the generation of damage in the solid body. In the present study, the following Tsai-Wu criterion 
for the anisotropic materials is introduced to evaluate the damage criterion of the CFRP laminated beam.

$$
\frac{\sigma_{T}^{2}}{F_{T t} F_{T c}}+\left(\frac{1}{F_{T t}}-\frac{1}{F_{T c}}\right) \sigma_{T}+\frac{\tau_{L T}^{2}}{F_{L T}^{2}}=1,
$$

where, $\sigma_{T}$ is the stress component transverse to the fiber direction, $\tau_{L T}$ is the shear stress for the side cross section of the beam, $F_{T t}$ and $F_{T c}$ are tensile and compression strengths (i.e., maximum stress at the failure point) in the plate transverse to the fiber direction, and $F_{L T}$ is shear strength for for the side cross section.

Generally, the tensile strength $F_{T c}$ is remarkably large compared with other strength. Thus, in the present strategy, we disregard $F_{T c}$ in the TsaiWu criterion. Taking the limit $F_{T c} \rightarrow \infty$, Tsai-Wu criterion can be simplified as follows.

$$
\frac{\sigma_{T}}{F_{T t}}+\frac{\tau_{L T}^{2}}{F_{L T}^{2}}=1 .
$$

Consequentially, the modified Tsai-Wu criterion can be expressed by the following quadratic function between normal stress $\sigma_{T}$ and shear stress $\tau_{L T}$.

$$
\sigma_{T}=-\frac{F_{T t}}{F_{L T}^{2}} \tau_{L T}^{2}+F_{T t}
$$

The quadratic approximation curve based on eq. (4) can be drawn from several experimental data of $\sigma_{T}$ and $\tau_{L T}$ at the initial fracture point estimated in finite element analysis. This approximation curve becomes the critical curve of the damage criterion for the CFRP laminated beam.

Figure 20 shows the criterion curve based on eq. (4) for the CFRP base laminates and CFRP laminates with the CNF interlayer. Since the experimental data widely vary, Fig. 20 shows only the six mid-range results from the 10 results (i.e., the two highest and lowest results are not shown). 
In Fig. 20, the normal stress $\sigma_{T}$ and shear stress $\tau_{L T}$ were evaluated on the each damage point as shown in Figs 9, 10, 11 and 12. The stress components on the each damage point can be determined by the interpolation using stress values on the nodal points obtained by FEM analyses.

It is seen that the experimental results for the CFRP base laminates satisfy the approximate equation of the damage criterion expressed by eq. (4). For the CFRP laminates toughened with the CNF interlayer, the experimental results tend to deviate from the approximate expression a little in the area where the interlaminar shear stgress becomes predominant.

Table 3 presents the tensile strength $F_{T c}$ and shear strength $F_{T t}$ calculated using the approximate equation (3). It is seen that the tensile strength $F_{T c}$ is greater for the CFRP base laminate than for the CFRP laminate toughened with a CNF interlayer. This is because the approximation curve for the toughened CFRP slightly deviates from the experimental data. In fact, the tensile strength of the two types of laminates are almost the same according to Fig. 20.

On the other hand, in the shear strength $F_{L T}$ is $20 \%$ higher for the CFRP toughened with the CNF interlayer than for the base laminate. The figure confirms that the critical curve of the damage criterion has expanded in the positive direction of the horizontal axis in the area where the compression normal stress $\sigma_{T}<0$ acts in the transverse (vertical) direction of the beam. That is, interlaminar strength can be improved by about $20 \%$ in the area of $\sigma_{T}<0$ by means of inserting the CNT interlayer between the prepreg layers. 


\subsection{Observation of the fracture surface}

The cross section and fracture surface of the CFRP specimens were observed using a scanning electronic microscope (SEM, Hitachi S-4100). First, the cross section was observed by cutting the specimen in a direction orthogonal to the fibers. Figures 21 and 22 show the SEM images of the cross section in which initial crack (delamination) was generated.

As shown in Fig. 21, in the CFRP base laminate, the stacked unidirectional prepregs integrate mutually, and a resin-rich layer between prepreg layers cannot be confirmed. Therefore, in the present case of CFRP base laminates, the initial crack does not necessarily occur between prepreg layers. However, delamination progressed in a comparatively straight line in the direction of the width of the beam. Although it is difficult to find the location of occurrence of the initial crack strictly as a practical matter, the primary crack is generated perhaps on the surface of the specimen, and seems to progress inside the specimen afterwards.

On the other hand, in the CFRP toughened with a CNF interlayer, the form of the crack propagation in the orthogonal cross section is more complex. Judging from the experiment results, the locations of initial damage were various like in the $\mathrm{CNF}$ interlayer, between $\mathrm{CNF}$ intgerlayer/CFRP prepreg and inside of the CFRP prepreg, etc. However, it seemed to be often that the damage occurred in the CFRP prepreg layer as shown in Fig. 22. It is understood that the crack progressed by the following a complex winding route in the prepreg layer, avoiding the 'high toughness' CNF interlayer.

Although it cannot be declared that the above explanation is a clear cause of the difference in the strength property between base laminate and 
CNF-toughened laminate, it seems that the difference of the fracture pattern in the cross section is one of the factors for the increase in the limit of the damage shown in Fig. 20.

Figures 23 and 24 show the fracture surfaces on the delamination of the two laminates observed with an SEM. No clear difference was found between the laminates in terms of the fracture surface. As discussed previously, interlaminar cracks in both kinds of specimens basically progressed in the prepreg layer. Although no difference can be found in this respect, there is one point that should be noted. In the CFRP toughened with the CNF interlayer, the CNF is inserted between prepreg layers in the forming process, and epoxy resin in the prepregs leaks into the interlayer during the baking process in the autoclave. Specifically, the fiber volume fraction of the prepreg layer should increase because of resin leakage into the interlayer. Consequentially, it is considered that not only the toughening effect of the CNF interlayer but also the increase in the volume fraction of the prepreg resulted in the difference in the strength property between the two laminates.

\section{Conclusion}

The criterion for the interlaminar strength of unidirectional CFRP laminates toughened with a CNF interlayer was discussed. Two types of unidirectional CFRP laminates were employed. One was a general unidirectional CFRP laminate made from carbon/epoxy prepregs using an autoclave. The other was a nano-modified CFRP laminate, in which the interfaces of the prepregs were toughened with a CNF interlayer.

To obtain the limit curve of the damage criterion for interlaminar fracture, 
two types of interlaminar strength tests were carried out. The first was a compression-type interlaminar strength test involving simple three-point bending with a short-type beam. The other was a tensile-type test applying shear tensile loading to specimens with a hole using a shear pin.

After finite element analyses, the criterion for interlaminar fracture of the CFRP laminates was investigated in detail using a modified 'Tsai-Wu' criterion. Taking the limit of compression strength, the Tsai-Wu criterion was simplified to a quadratic function between the normal stress and shear stress.

By inserting a CNF interlayer, the critical curve of the damage criterion increased about $20 \%$ in the area where the compression stress acts in the transverse direction of the beam. It is thought that the difference in the crack propagation form in the transverse cross section affected the property of interlaminar strength of the laminates. 


\section{ACKNOWLEDGEMENTS}

This research was supported by Regional Innovation Cluster Program of Nagano, granted by MEXT, Japan.

\section{References}

[1] Glover BM. History of development of commercial aircraft and 7E7 dreamliner. Aviation Engineering 2004;592:p.16-21.

[2] Sela N, Ishiai O, Banks-Sills, L. The effect of adhesive thickness on interlaminar fracture toughness of interleaved laminates specimens. Composite 1989;20(3): p.257-64.

[3] Singh S, Partridge IK. Mixed mode fracture in and interleaved carbon-fiber/epoxy composite. Composite Science and Technology 1995;55:p.319-27.

[4] Hojo M, Matsuda S, Tanaka M, Ochiai S, Murakami A. Mode I delamination fatigue properties of interlayer-toughened $\mathrm{CF}$ /epoxy laminates. Composites Science and Technology 2006;66:p.665-675.

[5] Hojo M, Ando T, Tanaka M, Adachi T, Ochiai S, Endo Y. Modes I and II interlaminar fracture toughness and fatigue delamination of $\mathrm{CF} / \mathrm{epoxy}$ laminates with self-same epoxy interleaf. International Journal of Fatigue, (In Press).

[6] Matsuda S, Hojo M, Ochiai S. Mesoscopic fracture mechanism of interleaf-toughened CFRP. JSME International Journal (Series A) 1997;40(4):p.423-29. 
[7] Oberlin A, Endo M, Koyama T. Filamentous growth of carbon through benzene decomposition. Journal of Crystal Growth 1976;32:p.335-49.

[8] Endo M. Grow carbon fibers in the vapor phase. CHEMTECH 1988;September:p.568-76.

[9] Iijima S. Helical microtubules of graphitic carbon, Nature 1991;354:p.56-58.

[10] Sandler J, Werner P, Shafer MSP, Demchuk V, Altstadt V. Carbonnanofibre-reinforced poly (ether ether ketone) composite. Composites 2002;33(Part A):p.1033-39.

[11] Choi Y., Sugimoto K., Song, S., Endo M., Production and Characterization of Polycarbonate Nanocomposite Sheets Reinforced with Vapor Grown Carbon Fibere Composites Part. A, 2006;37(11), p.1944-1951.

[12] Arai M, Kuwabara T, Hayashibe S, Takahashi Y, Endo M, Sugimoto K. Evaluation of mechanical property for carbon nano-fiber reinforced plastics. Transactions of the JSME, Series A (in Japanese) 2004;70(700):p.683-90.

[13] Arai M., Noro Y., Sugimoto K., Endo M., Mode I and mode II interlaminar fracture toughness of CFRP laminates toughened by carbon nanofiber interlayer, Journal of Composites Science and Technology, 2008;68(2), p.516-525.

[14] Li Y., Hori N., Arai M., Hu N., Fukunaga H., Improvement of interlami- 
nar mehcanical properties of CFRP laminates using VGCF, Composites: Part A, 2009;40, p.2004-2012.

[15] Tsai S. W. and Wu E. M., A general theory of strength for anisotropic materials, Journal of Composite Materials, 1971;5: p.58-80.

[16] ASTM D2344-84, Standard test method for apparent interlaminar shear strength of parallel fiber composites by short-beam method, ASTM Standards and Literature References for Composite Materials, 2nd Ed. (1990) ASTM, Philadelphia.

[17] ANSYS multiphisics, ANSYS Inc, http://www.ansys.com/.

[18] Suemasu H., Mechanics of Composite Materials (Introduction to Engineering Beginners), Baifukan, ISBN 978-4-563-06778-6 C3050, 2009, p.83, in Japanese. 
Table 1: Dimensions of the CFRP specimens.

\begin{tabular}{ccc}
\hline & Comp. Type & Tens. Type \\
\hline Length & $26.6 \mathrm{~mm}$ & $52.5 \mathrm{~mm}$ \\
\hline Width & $10.0 \mathrm{~mm}$ & $10.0 \mathrm{~mm}$ \\
\hline Height & $3.8-3.9 \mathrm{~mm}$ & $7.5-7.7 \mathrm{~mm}$ \\
\hline Number of Prepregs & $16 \mathrm{ply}$ & $32 \mathrm{ply}$ \\
\hline Support Length & $14 \mathrm{~mm}$ and $19 \mathrm{~mm}$ & $19 \mathrm{~mm}$ and $38 \mathrm{~mm}$ \\
\hline
\end{tabular}

Table 2: Elastic moduli of CFRP specimens.

\begin{tabular}{ccc}
\hline & Base laminate & With interlayer \\
\hline$E_{L}$ & $106.6 \mathrm{GPa}$ & $96.6 \mathrm{GPa}$ \\
\hline$E_{T}$ & $8.50 \mathrm{GPa}$ & $7.70 \mathrm{GPa}$ \\
\hline$G_{L T}$ & $4.65 \mathrm{GPa}$ & $3.63 \mathrm{GPa}$ \\
\hline$\nu_{L T}$ & 0.30 & 0.32 \\
\hline
\end{tabular}

Table 3: Critical tensile strength $F_{T t}$ and shear strength $F_{L T}$.

\begin{tabular}{lcc}
\hline & Base laminate & With interlayer \\
\hline Critical tensile strength $F_{T t}$ & $44.1 \mathrm{MPa}$ & $33.0 \mathrm{MPa}$ \\
Critical shear strength $F_{L T}$ & $41.8 \mathrm{MPa}$ & $52.2 \mathrm{MPa}$ \\
\hline
\end{tabular}



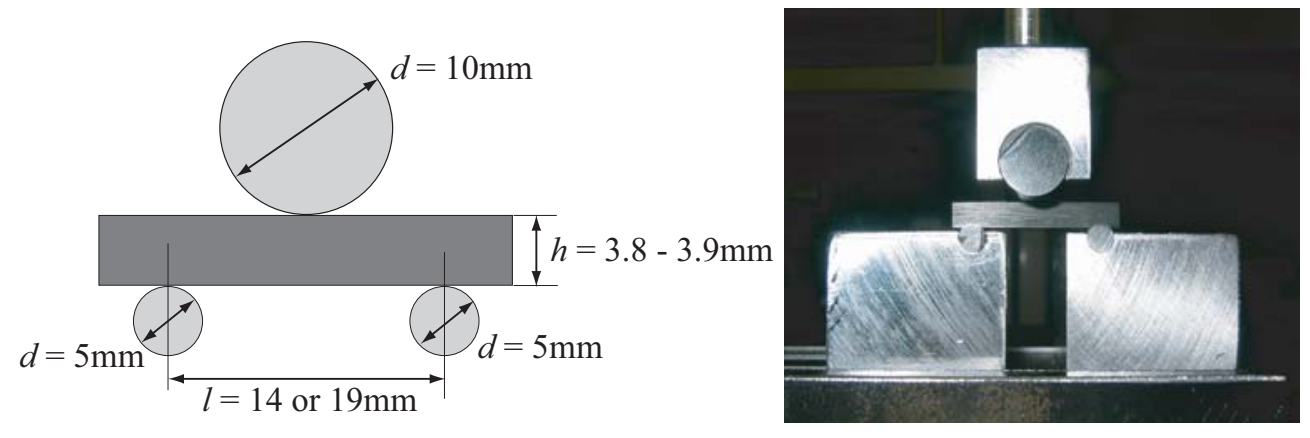

Figure 1: Compression-type interlaminar strength test.
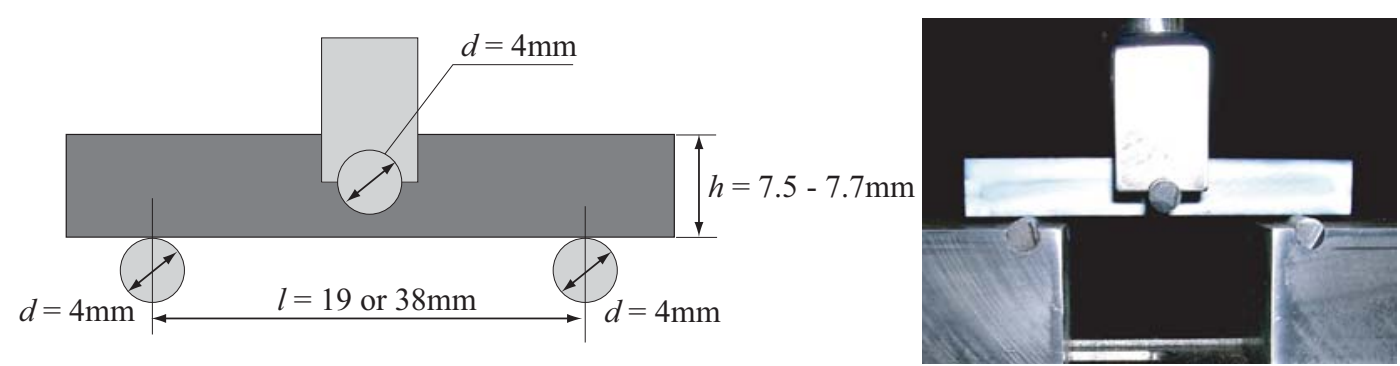

Figure 2: Tensile-type interlaminar strength test. 


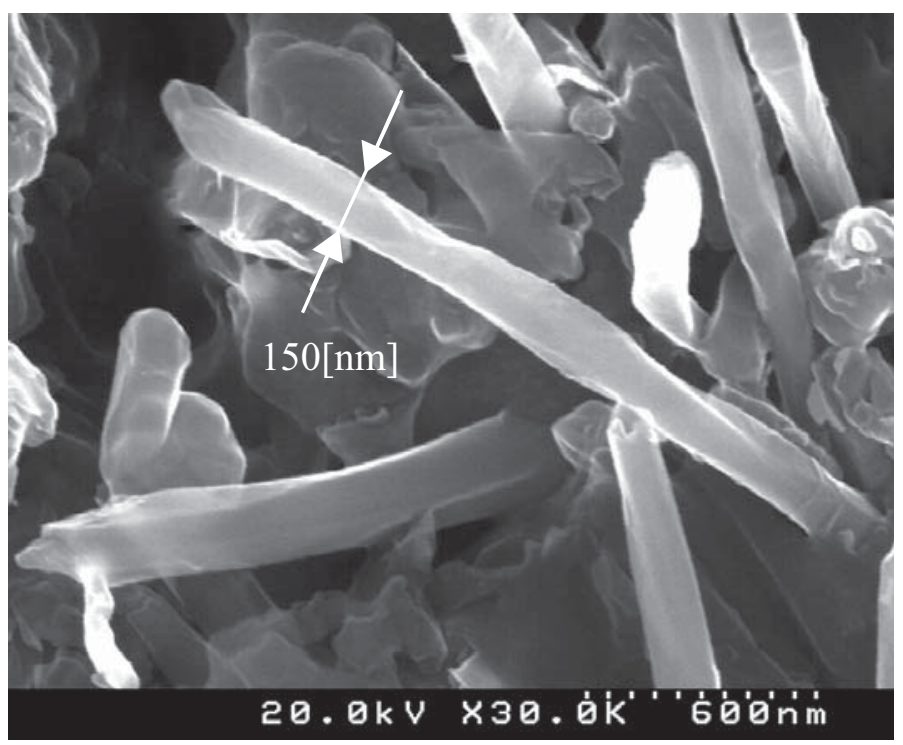

Figure 3: SEM image of VGCF.

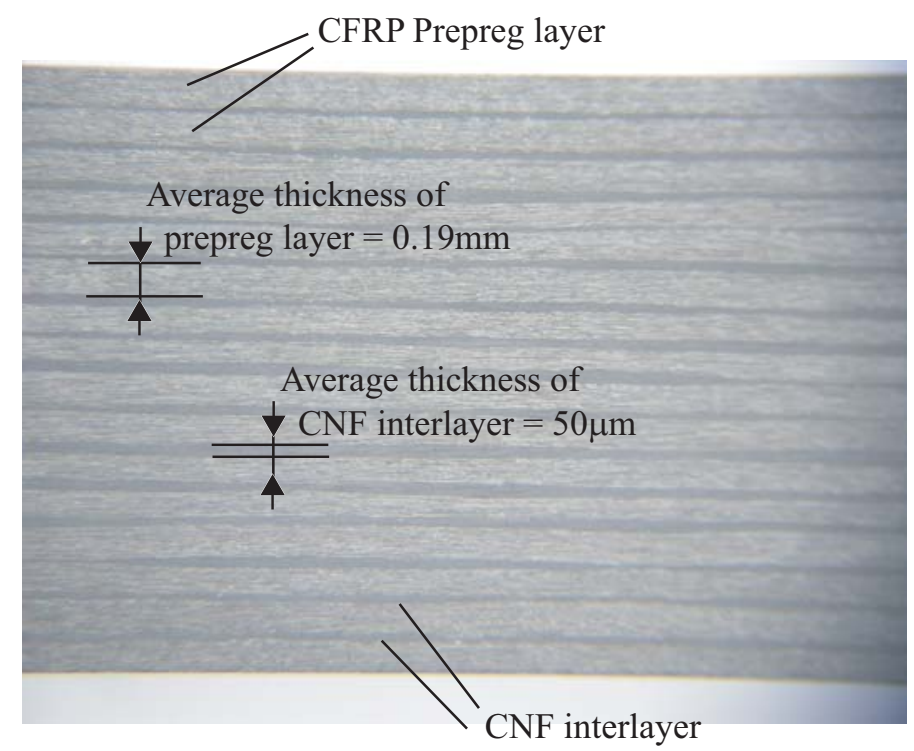

Figure 4: CFRP laminate toughened with a CNF interlayer. 


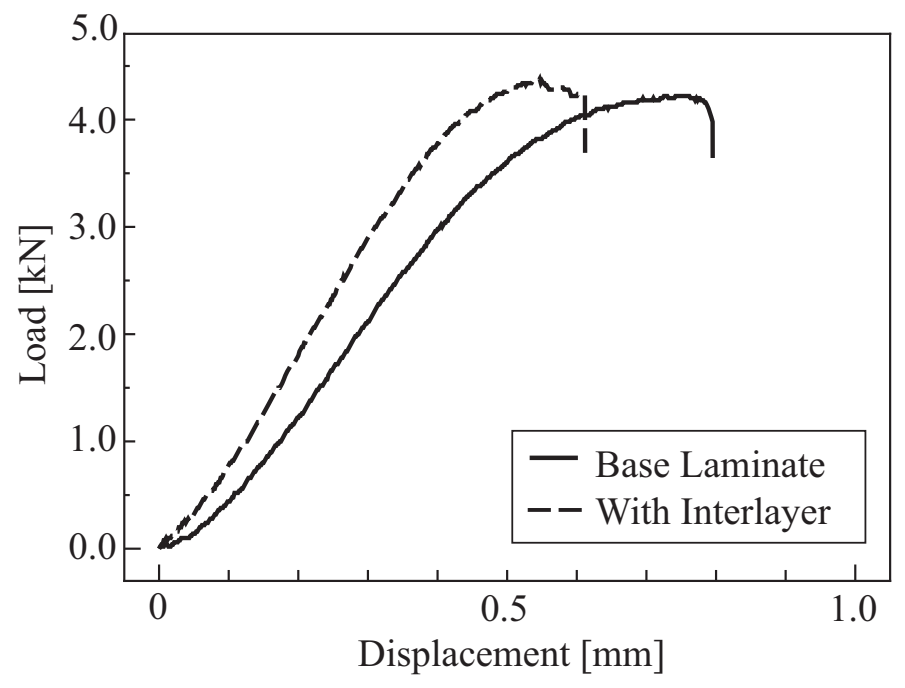

Figure 5: Load versus displacement of the CFRP laminates obtained in compression-type tests $(L=14 \mathrm{~mm})$.

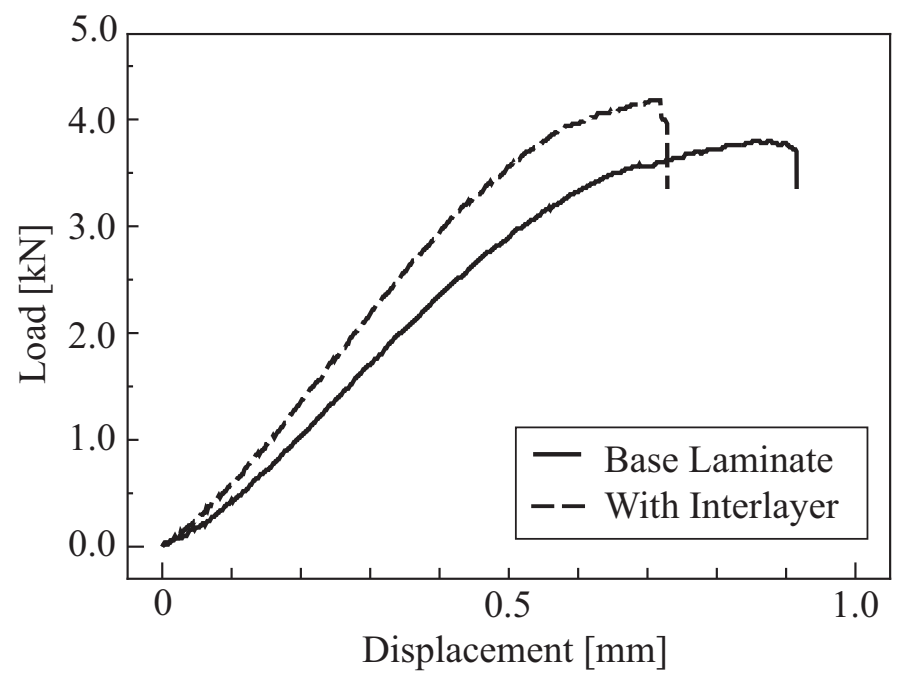

Figure 6: Load versus displacement of the CFRP laminates obtained in compression-type tests $(L=19 \mathrm{~mm})$. 


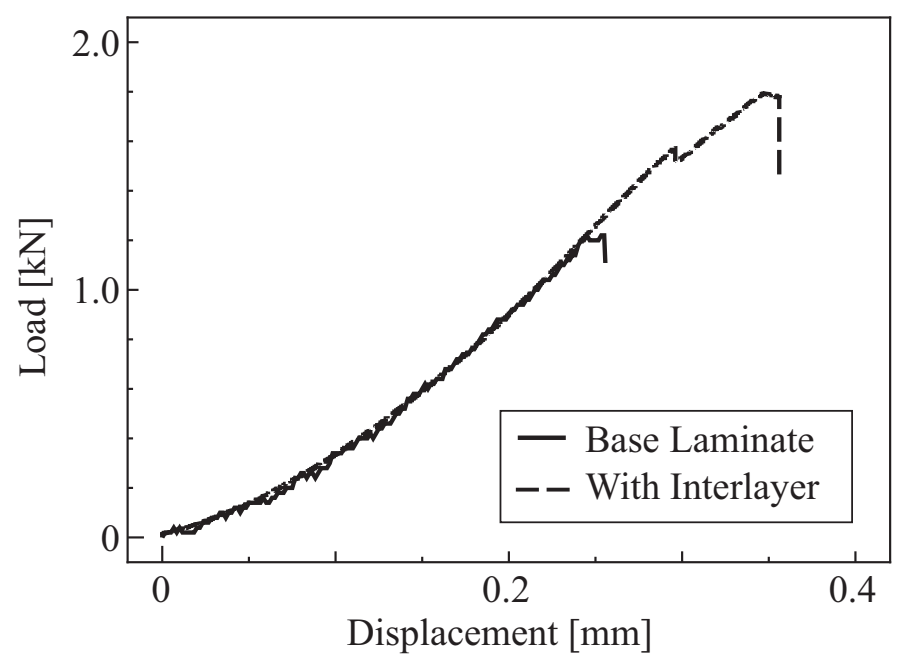

Figure 7: Load versus displacement of the CFRP laminates obtained in tensile-type tests $(L=19 \mathrm{~mm})$.

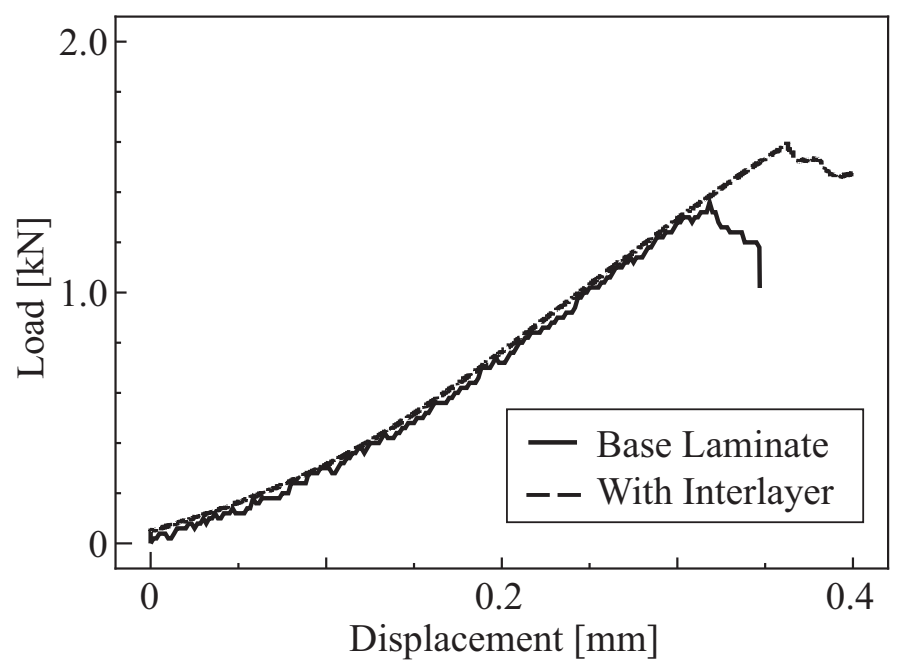

Figure 8: Load versus displacement of the CFRP laminates obtained in tensile-type tests $(L=38 \mathrm{~mm})$. 

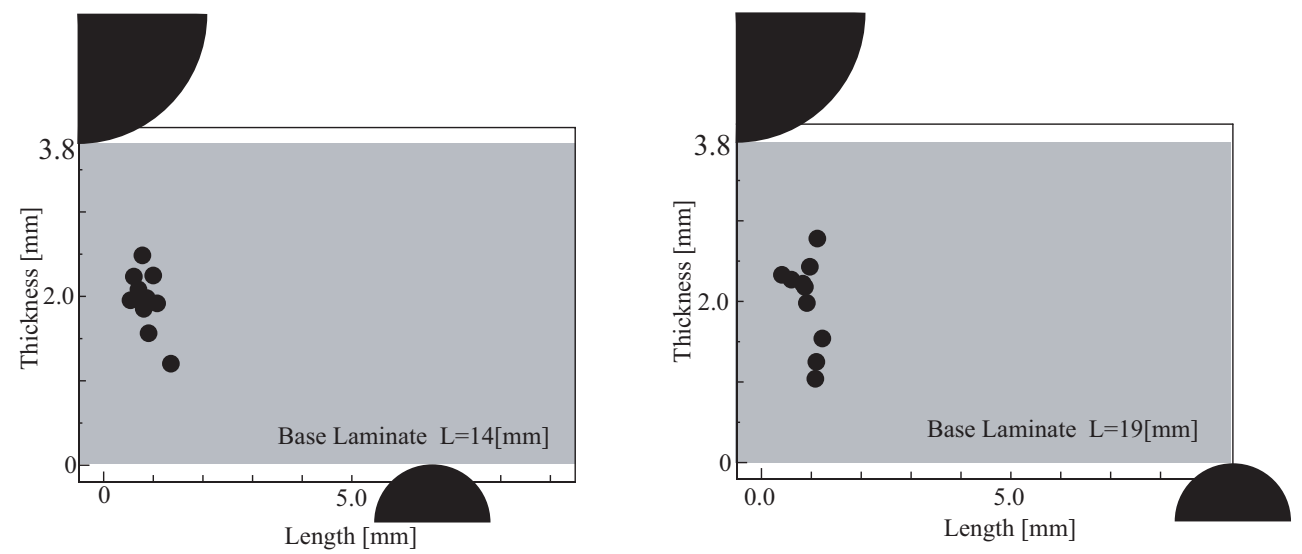

Figure 9: Fracture points in the CFRP base laminates obtained in compression-type tests.
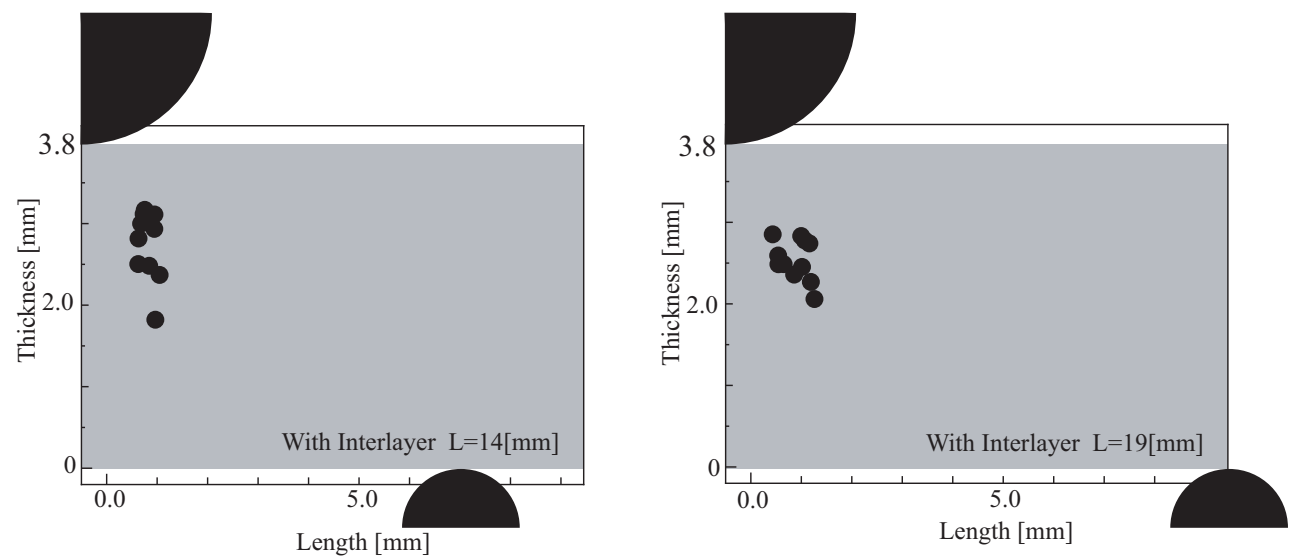

Figure 10: Fracture points in the CFRP with VGCF interlayer obtained in compressiontype tests. 

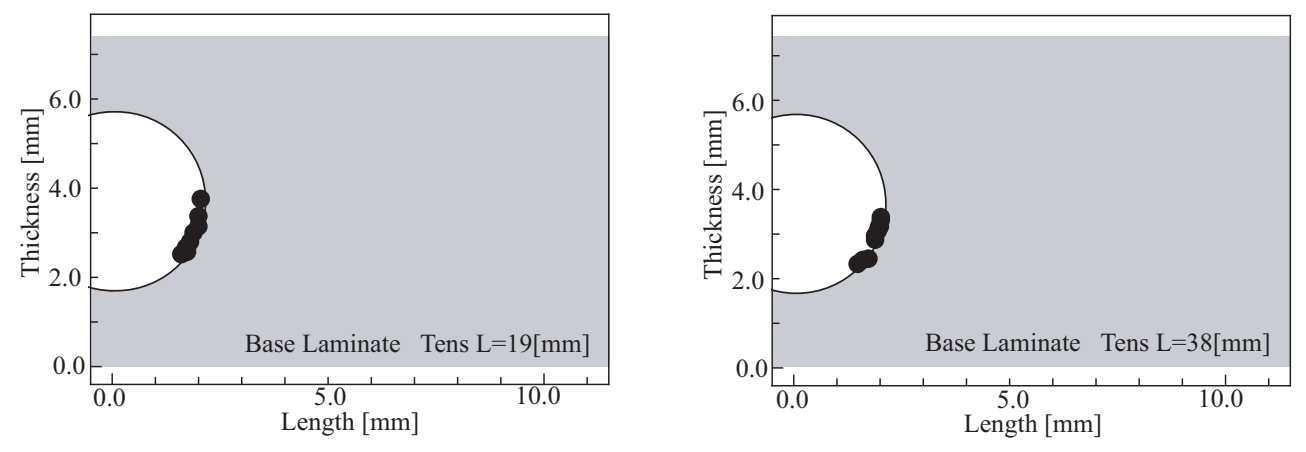

Figure 11: Fracture points in the CFRP base laminates obtained in tensile-type tests.
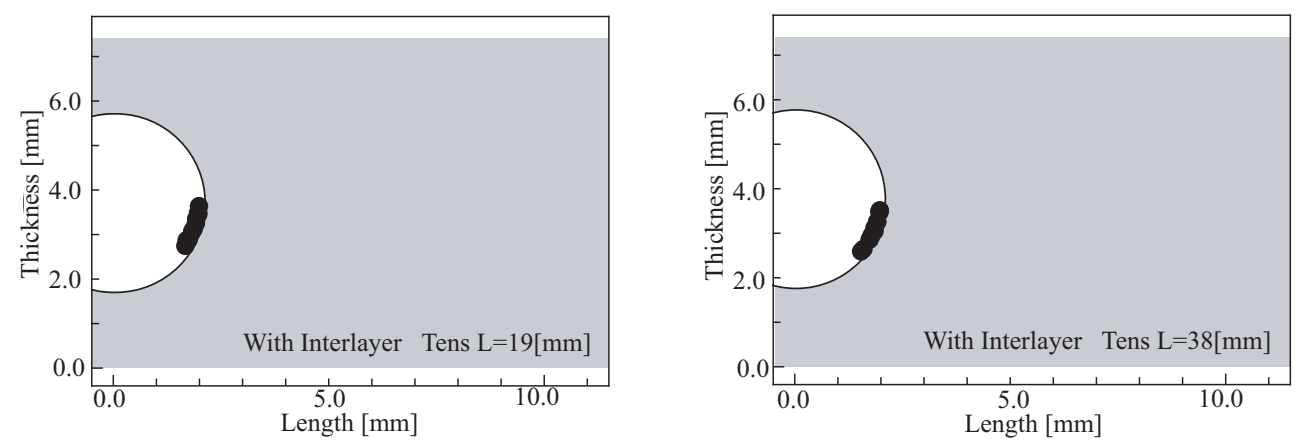

Figure 12: Fracture points in the CFRP with VGCF interlayer obtained in tensile-type tests. 


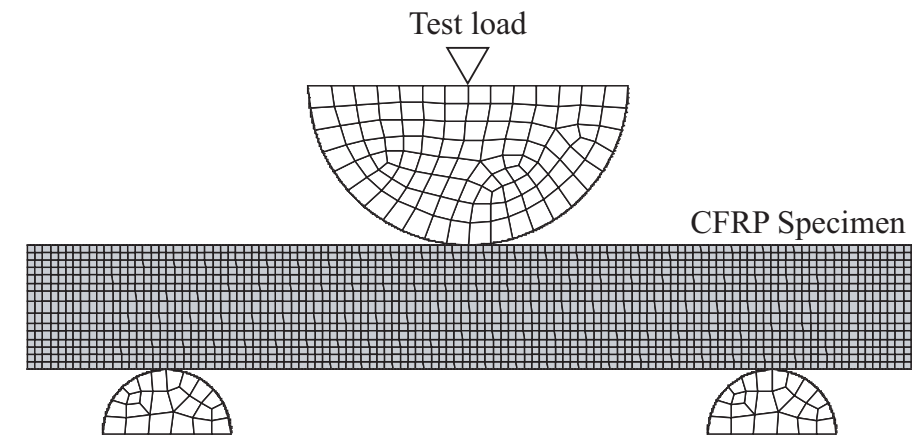

Figure 13: FEM model of CFRP laminates for compression-type tests $(l=19 \mathrm{~mm})$.

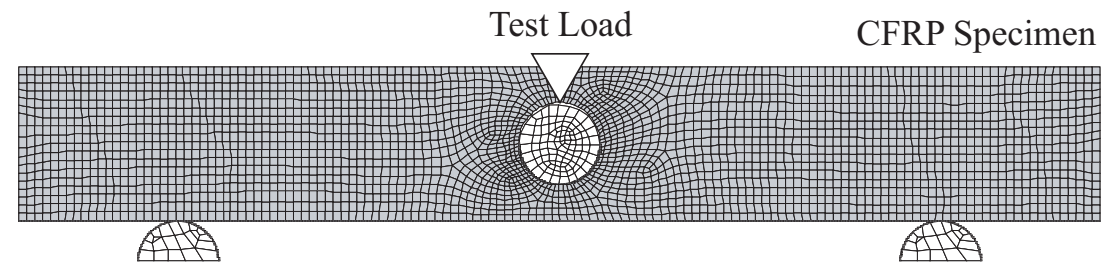

Figure 14: FEM model of CFRP laminates for tensile-type tests $(l=38 \mathrm{~mm})$. 


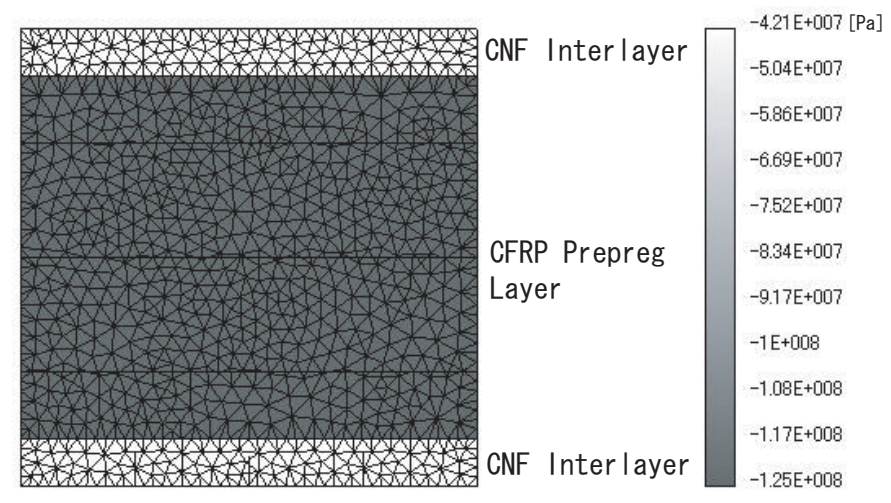

Figure 15: Normal stress distribution of $\sigma_{L}$ obtained by FEM with homogenized theory using the model of Fig. 13 on the point of initial damage.

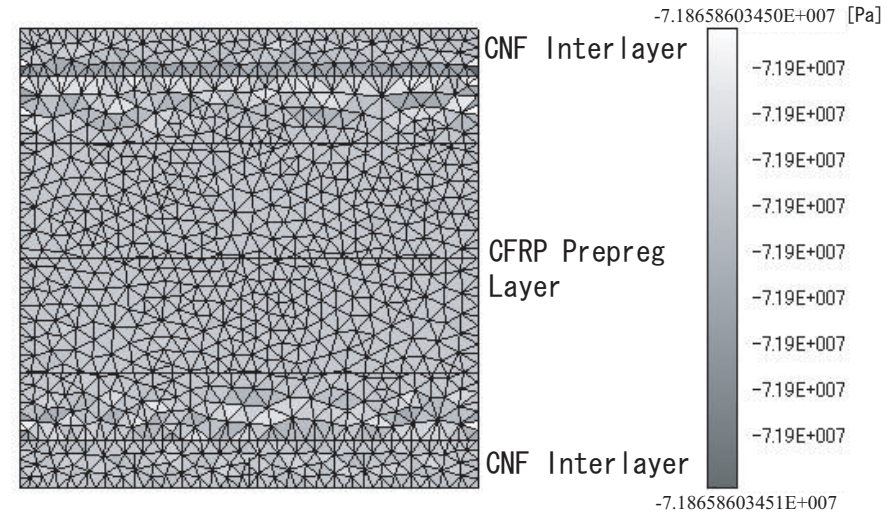

Figure 16: Normal stress distribution of $\sigma_{T}$ obtained by FEM with homogenized theory using the model of Fig. 13 on the point of initial damage. 


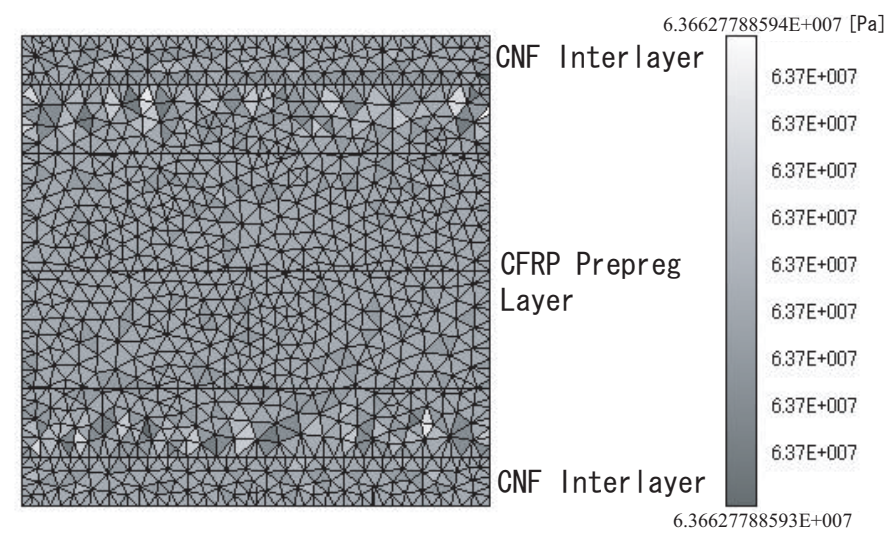

Figure 17: Shear stress distribution of $\tau_{L T}$ obtained by FEM with homogenized theory using the model of Fig. 13 on the point of initial damage. 


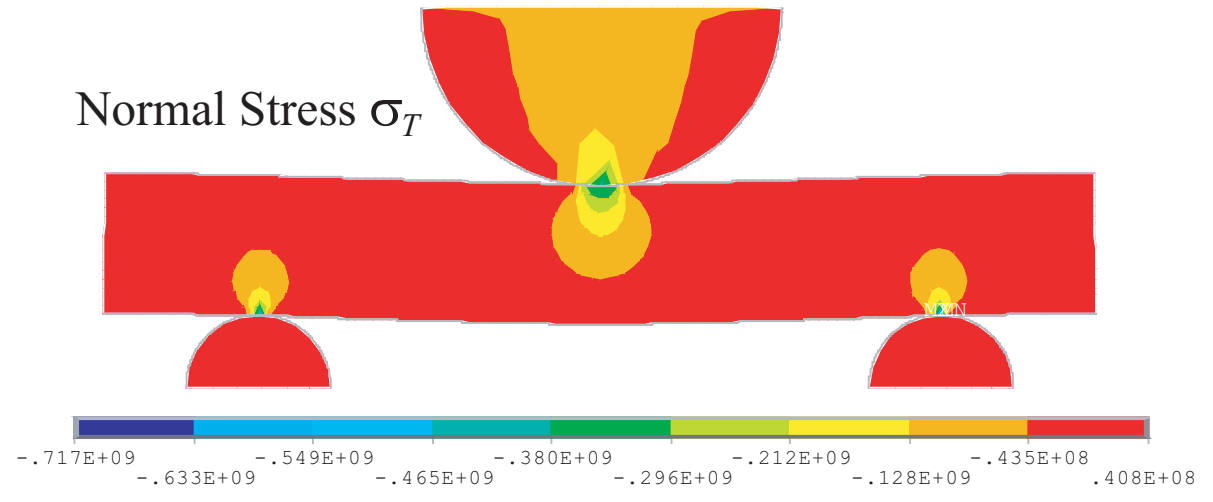

Figure 18: Contour figures of normal stress $\sigma_{T}$ estimated by FEM analysis (base laminate, compression-type model, $l=19 \mathrm{~mm})$.

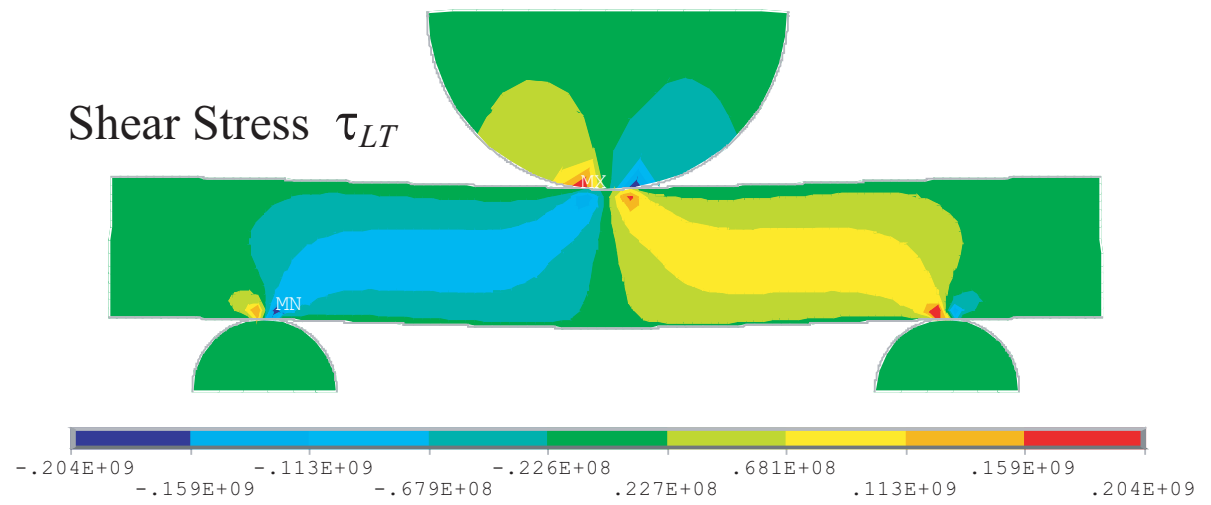

Figure 19: Contour figures of shear stress $\tau_{L T}$ estimated by FEM analysis (base laminate, compression-type model, $l=19 \mathrm{~mm}$ ). 


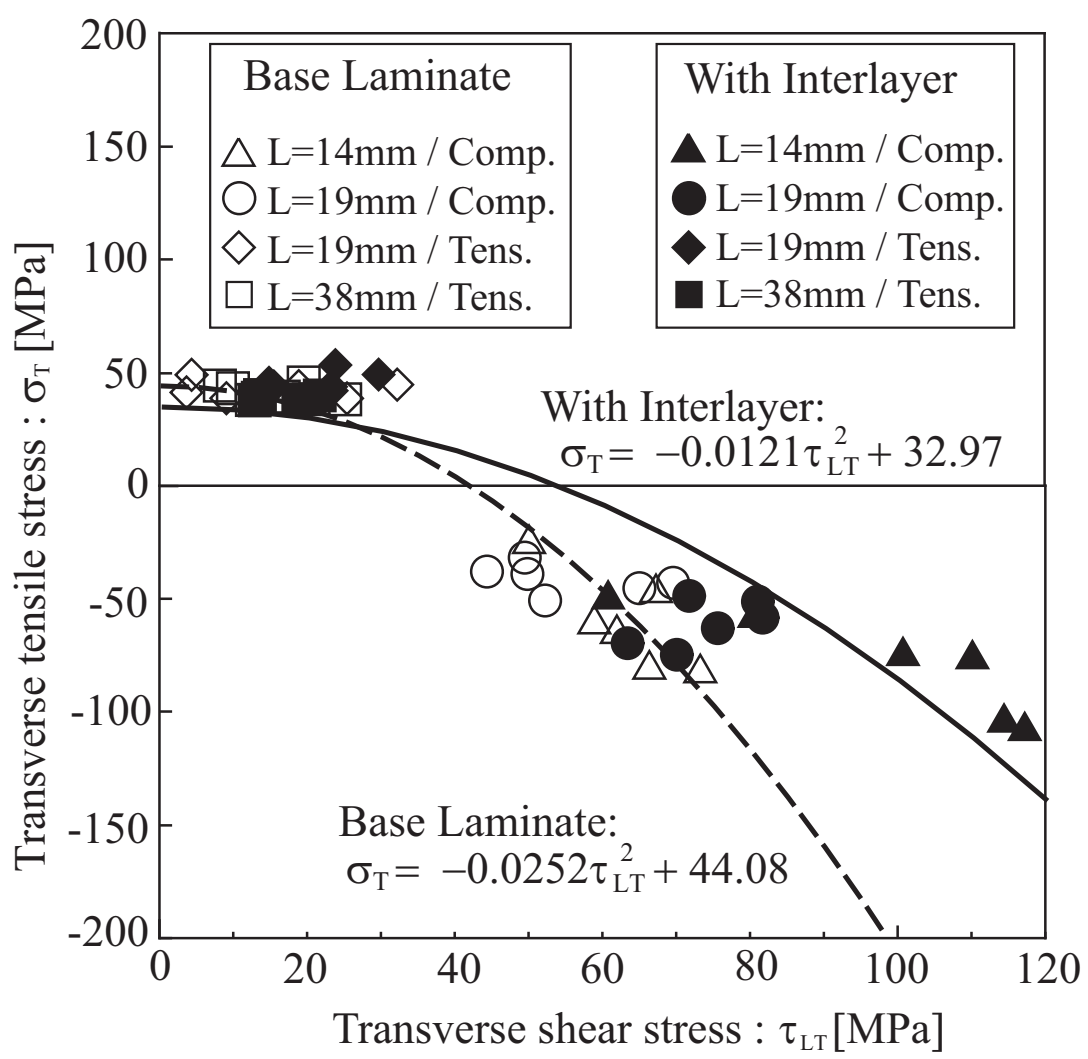

Figure 20: Summary of interlaminar fracture criterion of CFRP laminates. 


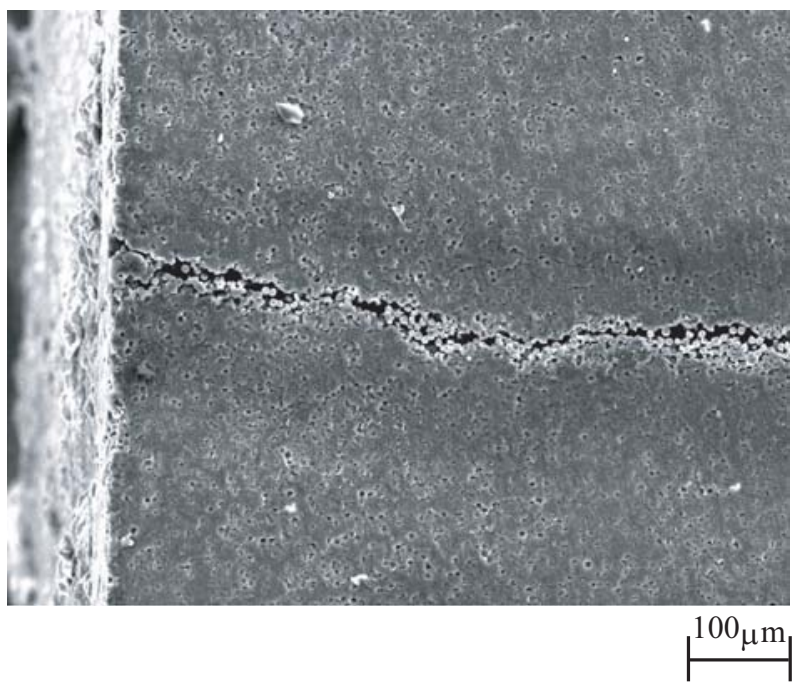

Figure 21: SEM image of cross section transverse to the fiber direction of CFRP base laminates ( $L=14 \mathrm{~mm}$, compression-type test).

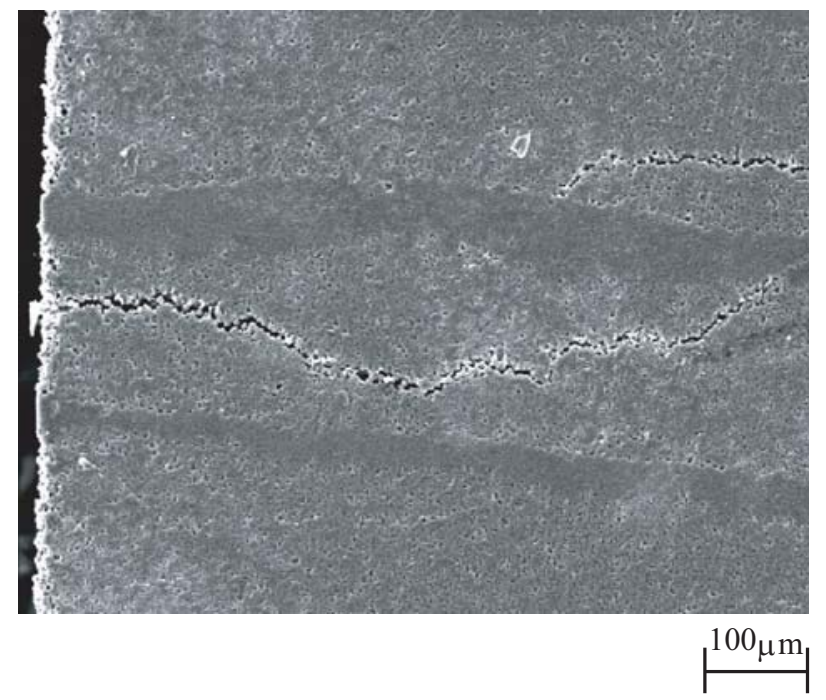

Figure 22: SEM image of cross section transverse to the fiber direction of CFRP laminates toughened by CNF interlayer ( $L=14 \mathrm{~mm}$, compression-type test). 


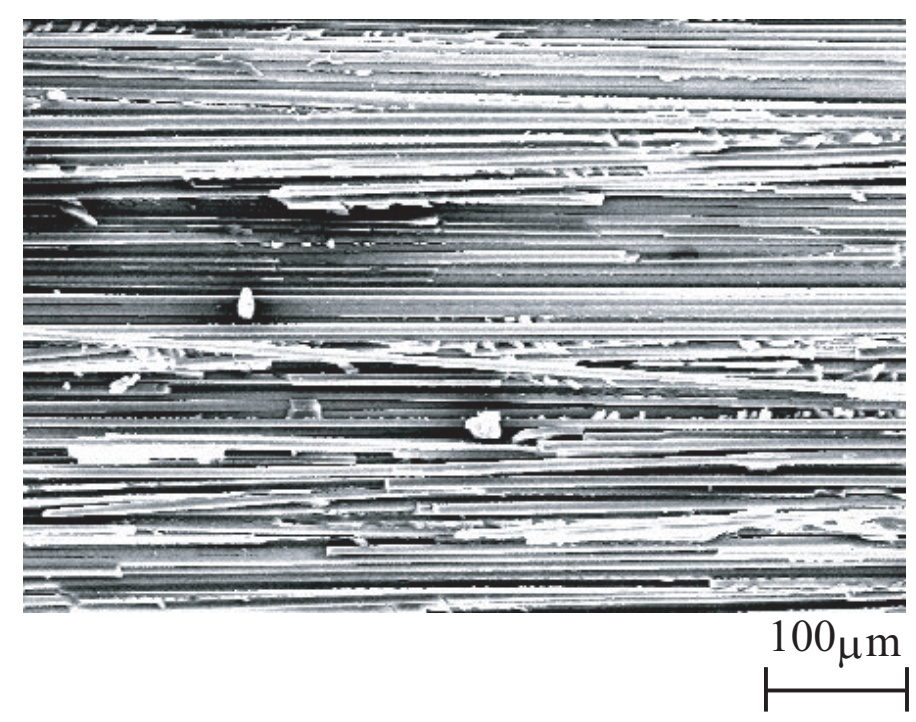

Figure 23: SEM image of fracture surface of CFRP base laminates $(L=14 \mathrm{~mm}$, compression-type test).

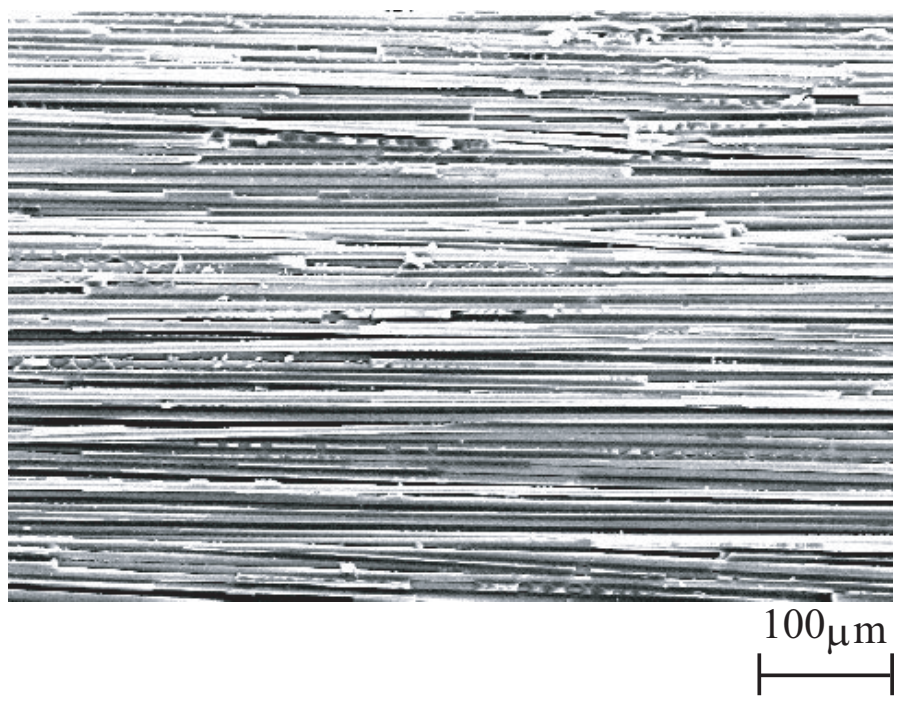

Figure 24: SEM image of fracture surface of CFRP laminates toughened by CNF interlayer ( $L=14 \mathrm{~mm}$, compression-type test). 